\title{
The Role of Nutrition in Preventive Medicine: The Place of Street Food in International Gastronomy and Health Development
}

Judit Molnár ${ }^{1}$ and Mahendra Pal ${ }^{2 *}$

${ }^{1}$ Dietitian, MSc in Food Safety and Quality Engineering; Ph.D. in Food Sciences -Palánkutca, Mosonmagyaróvár, Hungary.

${ }^{2}$ Narayan Consultancy on Veterinary Public Health and Microbiology- Anand, Gujarat, India.

*Corresponding author: Mahendra Pal, Narayan Consultancy on Veterinary Public Health and Microbiology- Anand, Gujarat, India.

Received date: May 17, 2021; Accepted date: May 24, 2021; Published date: May 31,2021

Citation: Molnár J., and Mahendra Pal. (2021). The Role of Nutrition in Preventive Medicine: The Place of Street Food in International Gastronomy and Health Development. J. Nutrition and Food Processing, 4(4); DOI:10.31579/2637-8914/053

Copyright: (C) 2021, Mahendra Pal, This is an open access article distributed under the Creative Commons Attribution License, which permits unrestricted use, distribution, and reproduction in any medium, provided the original work is properly cited.

Abstract
Nowadays, due to the pandemic, preventive medicine also plays a prominent role in medical science. In addition
to physical activity or techniques used in alternative medicine (acupuncture, forms of massage, yogic exercise
etc.), the science of meditation has become the part of preventive medicine thanks to quantum physics,
epigenetics, metaphysics, neuroplasticity, and psychoneuroimmunology. Firstly, we examined the role of
nutrition science in preventive medicine in the manuscript. Therefore, we present foods that reinforce the street
food philosophy while being healthy and promoting health improvement. Furthermore, these foods can be used
as part of various diets. The manuscript contributes to the health promoting effect of nutrition science and
gastronomy and its role in preventive medicine.
Keywords: gastronomy; health promotion; nutrition science; preventive medicine; street food; restaurant
hospitality

\section{Introduction}

In recent years and in the current pandemic, preventive and alternative medicine have also played a prominent role in addition to the traditional medical science. Among the most important areas of preventive medicine [1-3] include various forms of physical activity and physical health promotion [4]. Techniques and natural remedies used in alternative medicine such as traditional Chinese medicine, also contribute to disease prevention [5]. In the comprehensive study of preventive medicine, the maintenance of mental health also plays a prominent role in a variety of ways. Stress management techniques include the science of meditation as well $[6,7]$. This is due to quantum physics [8-10], metaphysics [9], neuroplasticity [11] and psychoneuroimmunology [12] appearing in meditation. The essence of the science field is that objective perception is replaced by subjective perception (https://www.youtube.com/watch?v=Tpuwm7cmp1M).

The role of nutrition in science and preventive medicine has already been demonstrated in practice and in a number of articles [13]. Outstanding among these are the research results achieved in fermentation biotechnology which revealed a significant innovation in the context of vitamin supplementation of yeast strains, among others [14]. In addition, foods that stimulate the immune system require increased attention due to the COVID-19 pandemic [15]. We examined the role of street food, which can be considered the future of hospitality in health promotion and preventive medicine in the manuscript.

\section{In the footsteps of street food}

Nowadays, dishes that are simple, tasty and can be eaten on the go are becoming more and more popular. So this is the essence of street food which is slowly replacing traditional restaurant food saving quality time for consumers and also adapts to the pandemic. The concept of street food is known worldwide but it has been written about in few articles. The street food hospitality form can be seen as the future of restaurant hospitality. In addition to the best known fast foods, it already has an extremely wide selection $[16,17]$.

However, in some countries and specific areas, there are significant deficiencies in compliance with the hygiene regulations required by the quality assurance systems of street food restaurants and in the supply of healthy street food. The development of this area is very essential from the hygienic and food safety point of view [18-21].

Healthy food ideas following the street food philosophy as a part of health promotion and disease prevention through the science of gastronomy

Firstly, we have prepared dishes (Figure 1-8) that are easy to create, high quality, healthy and innovative for consumers following the street food philosophy in our manuscript. In addition, these foods can be useful members of special diets and helping to maintain a healthy lifestyle. 


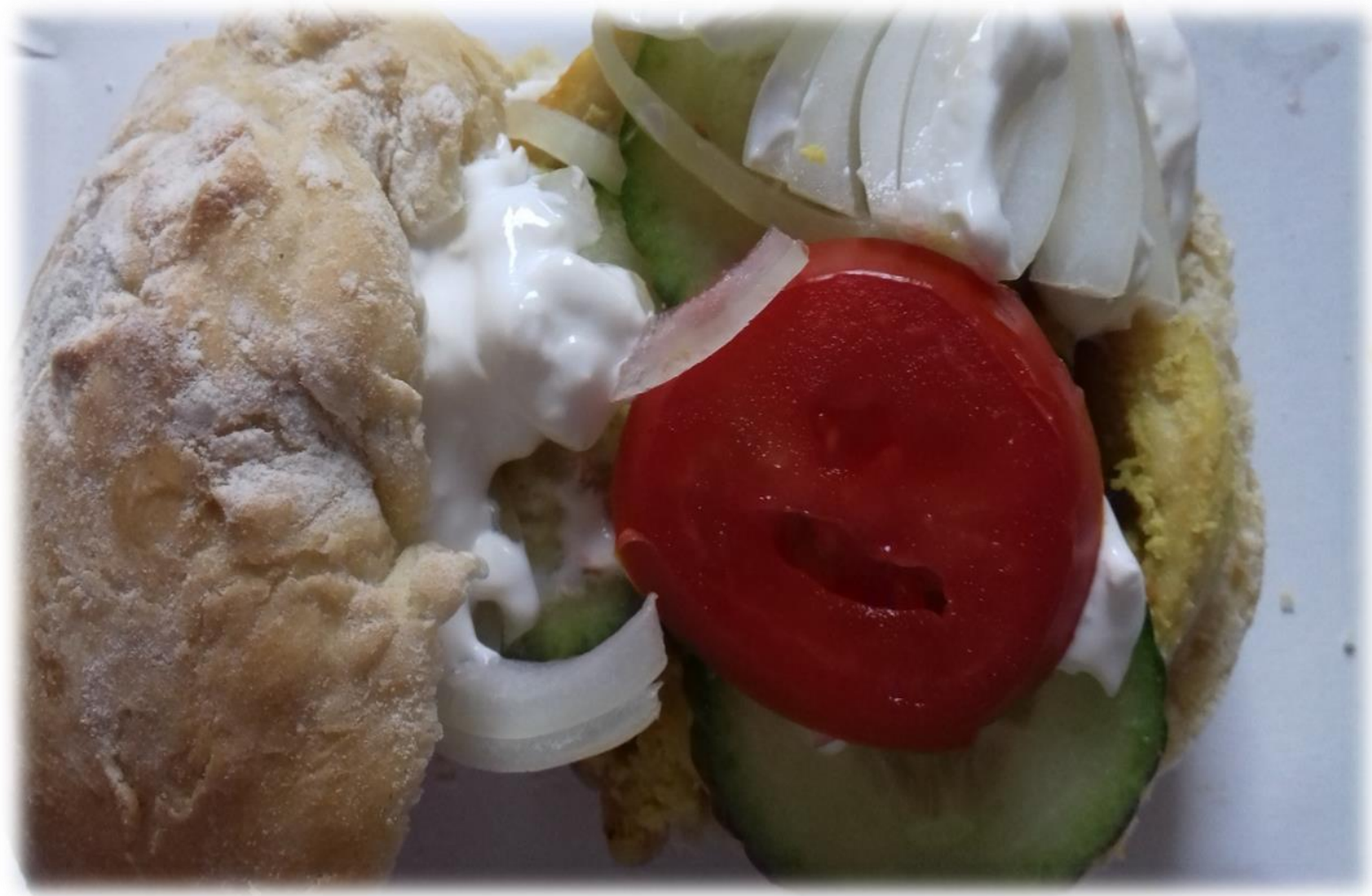

Figure 1. Buns with vegetables, chicken and garlic sauce (Own cuisine)

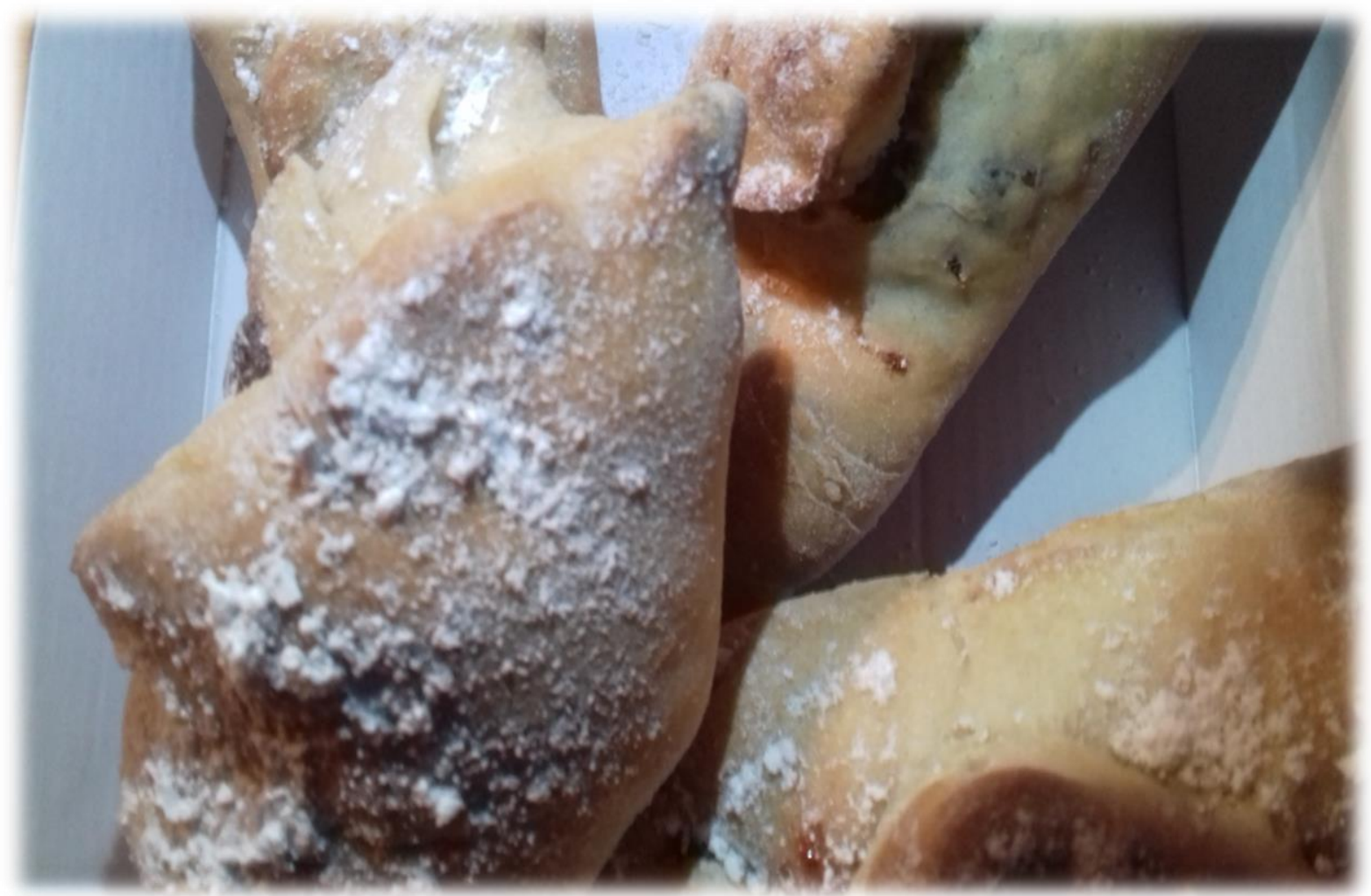

Figure 2. Rye flour pastry with plum jam and dark chocolate (Own cuisine) 


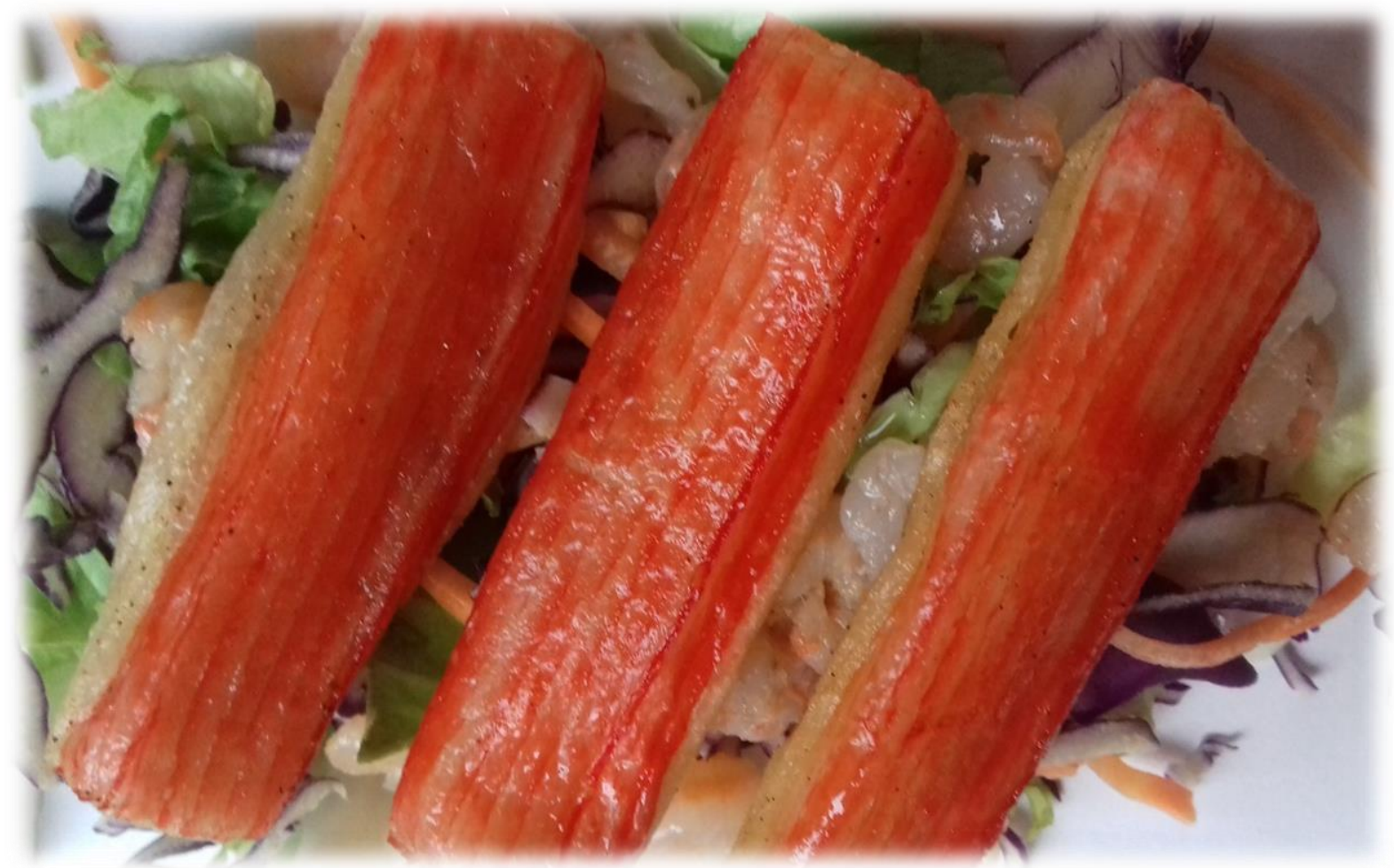

Figure 3. Salad mixture with fried surimi sticks and cocktail prawns (Own cuisine)

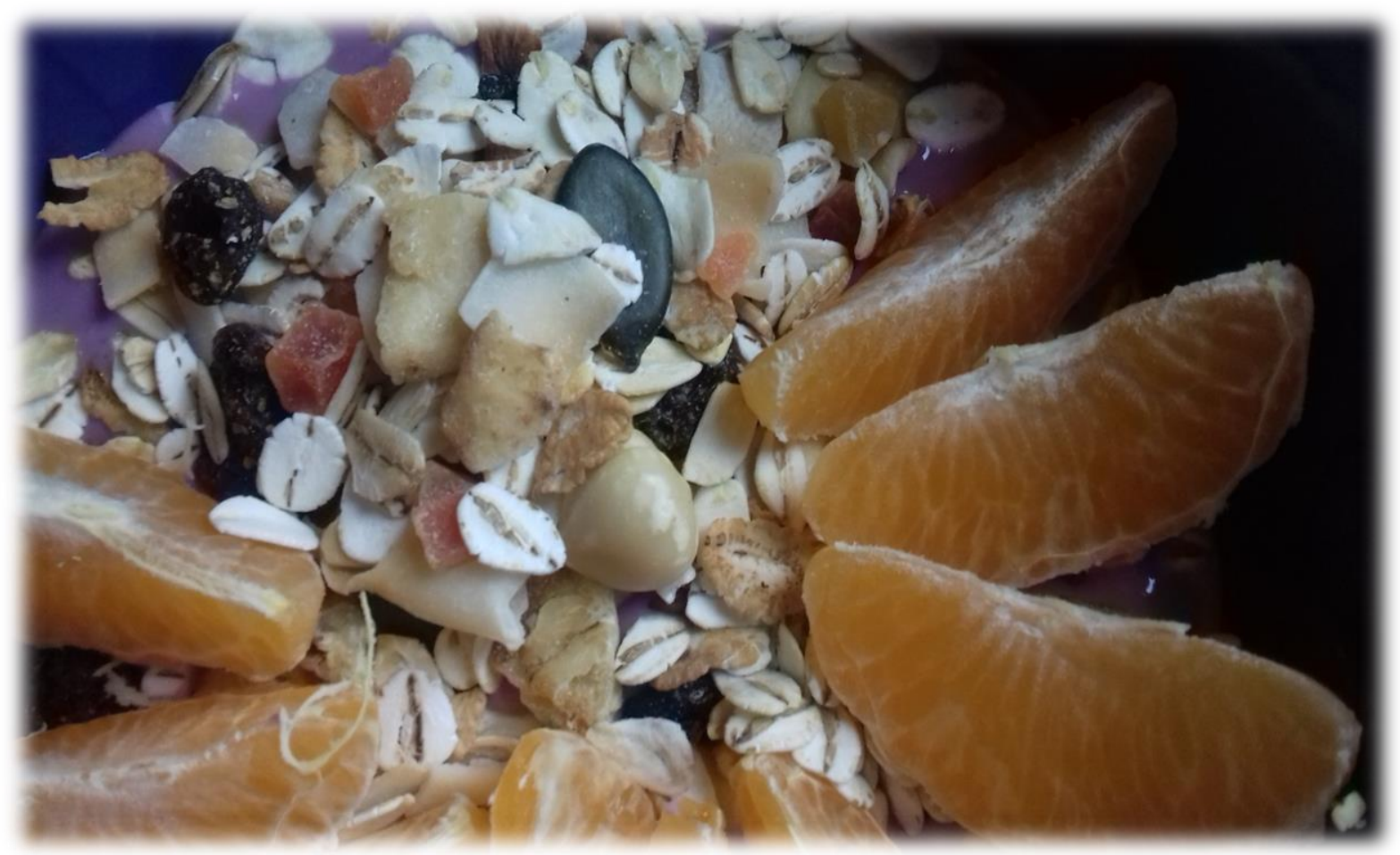

Figure 4. Plant based blueberry yogurt with muesli and mandarin (Own cuisine) 


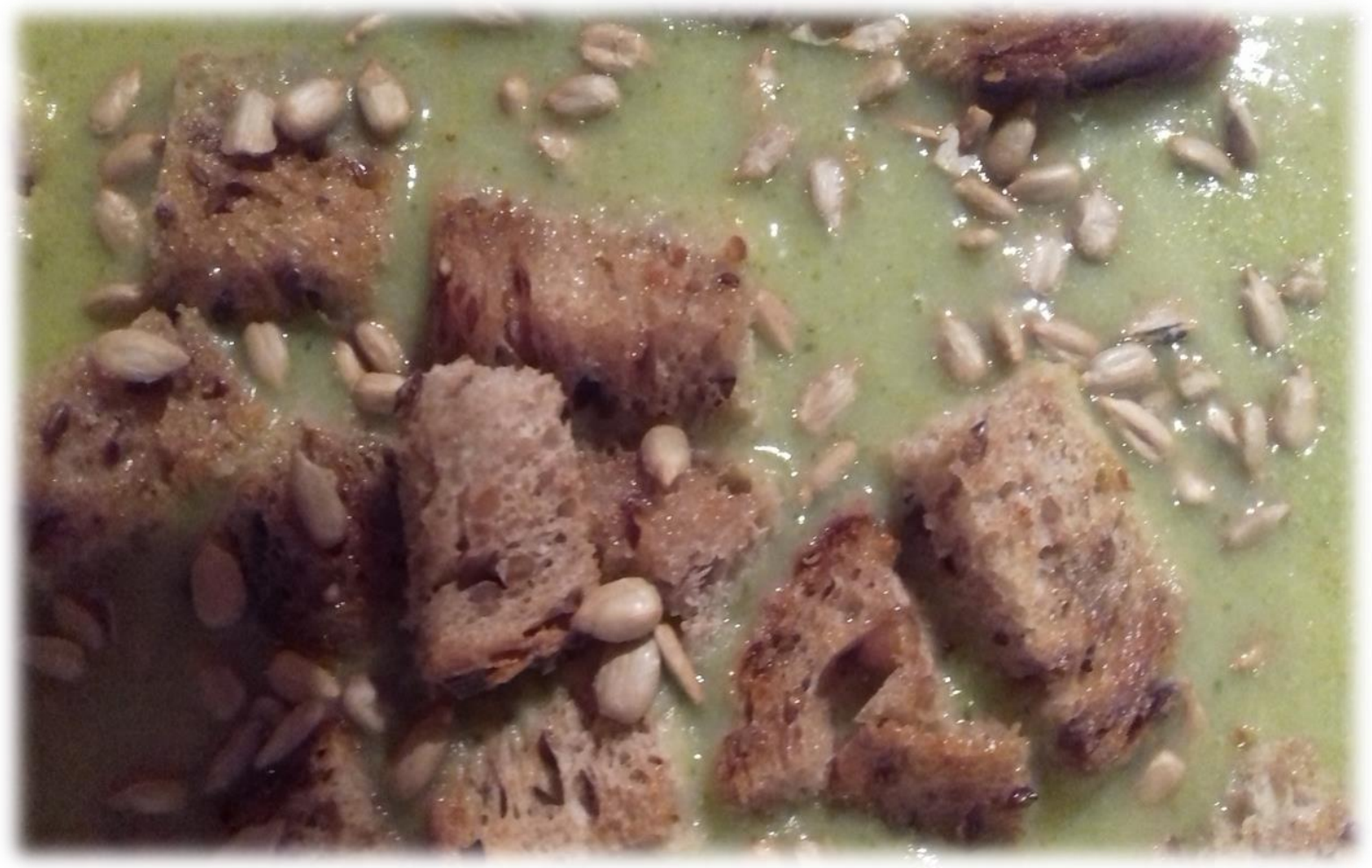

Figure 5. Broccoli cream soup with seeds and toast (Own cuisine)

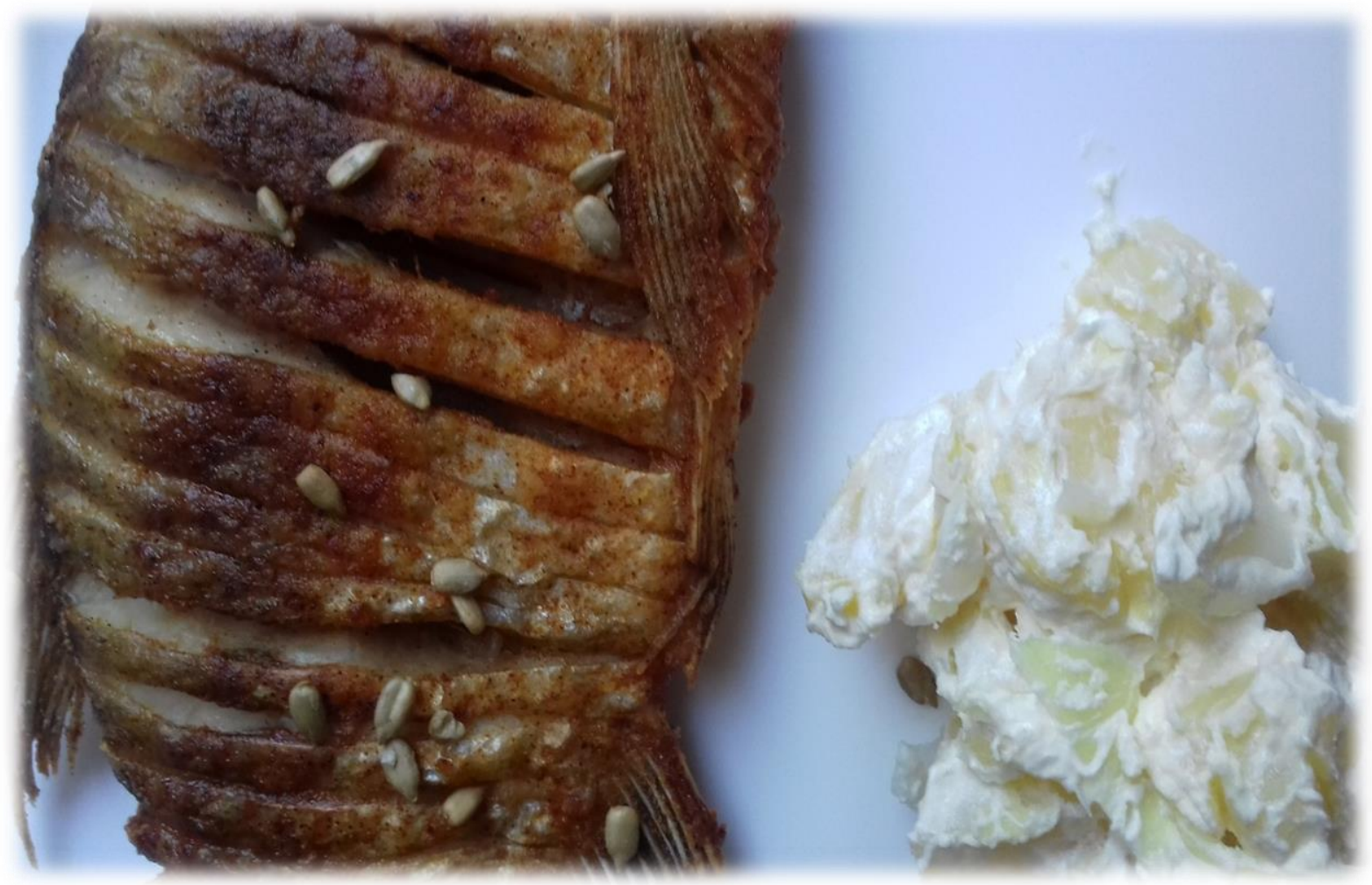

Figure 6. Fried fish with lactose-free potato-onion salad (Own cuisine) 


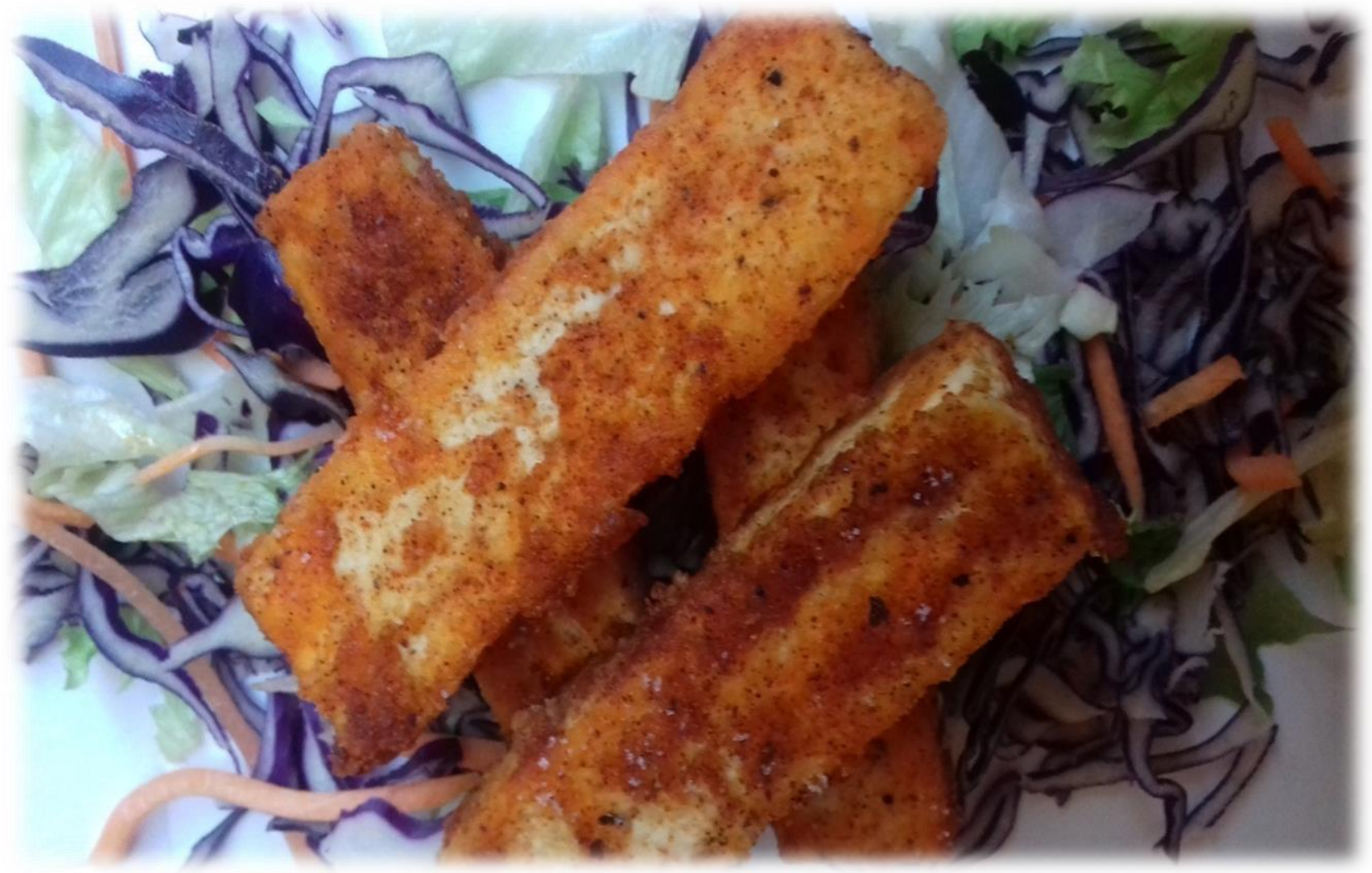

Figure 7. Tofu with vegetable garnish (Owe cuisine)

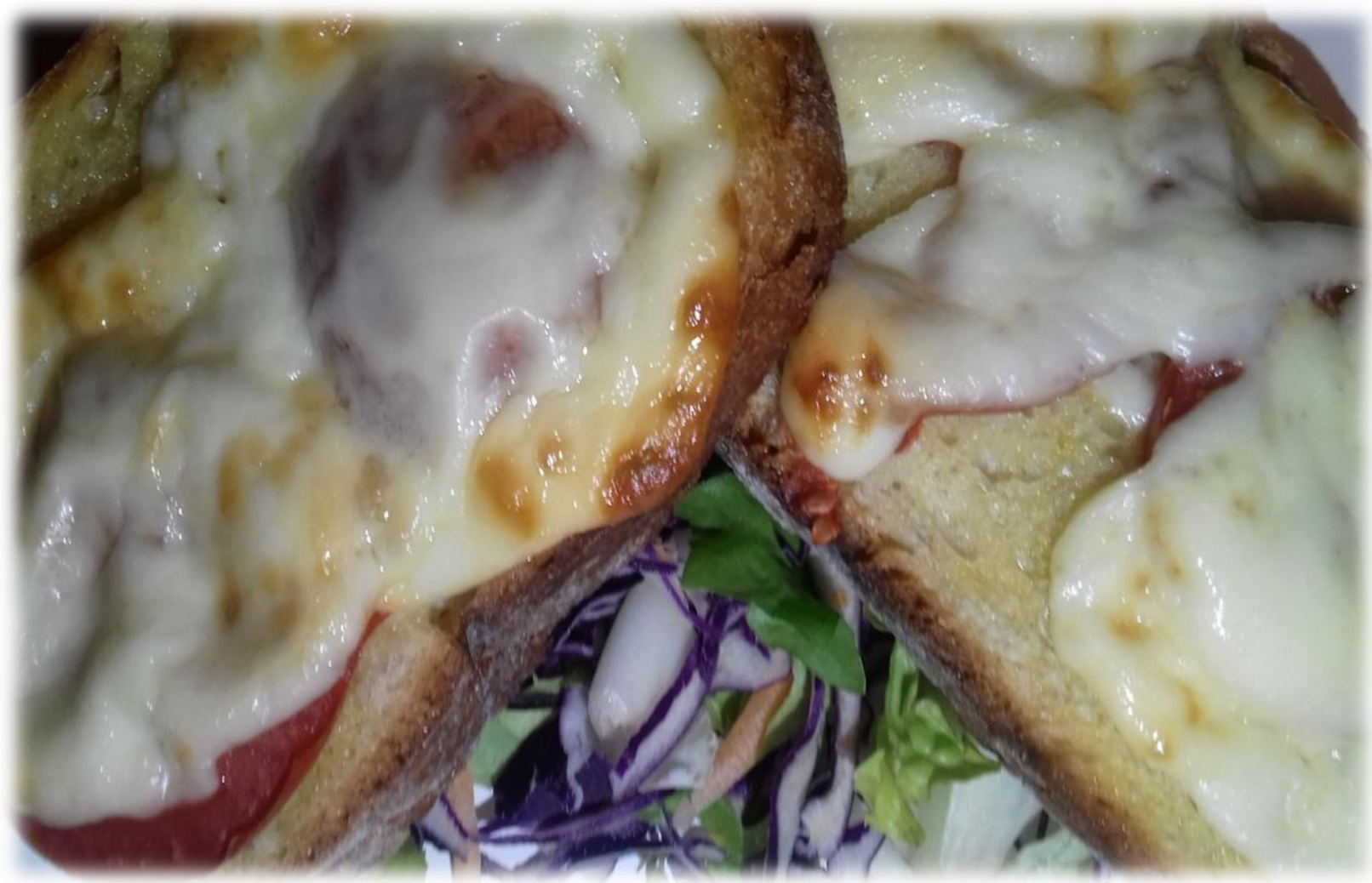

Figure 8. Sandwich variations (Own cuisine) 


\section{Conclusion}

The main goal of our manuscript is to develop a field of nutrition science that can be used as part of preventive medicine. Therefore, with the help of gastronomic science, we prepared and presented street food dishes (buns with vegetables, chicken and garlic sauce; rye flour pastry with plum jam and dark chocolate; salad mixture with fried surimi sticks and cocktail prawns; plant-based blueberry yogurt with muesli and mandarin; broccoli cream soup with seeds and toast; fried fish with lactose-free potato-onion salad; tofu with vegetable garnish; sandwich variations). These dishes follow the philosophy of street food while being healthy, quick to prepare and high quality as well as well-suited as part of special diets. We hope to contribute to the full understanding of street food and to the development of their role in nutrition science as part of preventive medicine.

\section{Acknowledgements}

The authors are very thankful to Prof. Dr. R.K. Narayan for his suggestions during the preparation of manuscript and Anubha Priyabandhu for computer help.

\section{Contribution of authors}

All the authors contributed equally. They read the final version, and approved it for the publication.

\section{Conflict of interest}

The authors declare that they do not have conflict of interest.

\section{Source of financial grant}

There was no financial support for this manuscript.

\section{References}

1. Jani A A, Trask J, Ali A (2015): Integrative medicine in preventive medicine education: Competency and curriculum development for preventive medicine and other specialty residency programs. American Journal of Preventive Medicine.49:S222-S229.

2. Trilk J, Nelson L, Briggs A, Muscato D (2019): Including lifestyle medicine in medical education: Rationale for American College of Preventive Medicine/American Medical Association Resolution 959. American Journal of Preventive Medicine.56:e169-e175.

3. Jadotte Y T, Lane D S (2021): Core functions, knowledge bases and essential services: A proposed prescription for the evolution of the preventive medicine specialty. Preventive Medicine.143:16.

4. Su X, McDonough D J, Chu H, Quan M, Gao Z (2020): Application of network meta-analysis in the field of physical activity and health promotion. Journal of Sport and Health Science.9:511-520.

5. Wang Y (2019): The scientific nature of traditional Chinese medicine in the post-modern era. Journal of Traditional Chinese Medical Sciences.6:195-200.

6. Lenhart L, Steiger R, Waibel M, Mangesius S, Grams A. E, Singewald N, Gizewski E R (2020): Cortical reorganization processes in meditation naïve participants induced by 7 weeks focused attention meditation training. Behavioural Brain Research.395:1-8.
7. Schröter M, Cramer H (2021): Prevalence and predictors of yogic breathing and meditation use - A nationally representative survey of US adult yoga practitioners. Complementary Therapies in Medicine.56:1-3.

8. Crus-Hastenreiter R (2015): Analogies in high school classes on quantum physics. Procedia Social and Behavioral Sciences.167:38-43.

9. Fingelkurts A A, Fingelkurts A A, Neves C F H, KallioTamminen T (2019): Brain-mind operational architectonics: At the boundary between quantum physics and eastern metaphysics. Physics of Life Reviews.31:122-133.

10. Burns A. M, Gräff J (2021): Cognitive epigenetic priming: leveraging histone acetylation for memory amelioration. Current Opinion in Neurobiology.67:75-84.

11. Gil R, Fernandes F F, Shemesh N (2021): Neuroplasticity - driven timing modulations revealed by ultrafast functional magnetic resonance imaging. Neuroimage.225:1-16.

12. Moriarity D P, Alloy L B (2020): Beyond diagnoses and total Symptom Scores: Diversifying the level of analysis in psychoneuroimmunology research. Brain Behavior and Immunity.89:1-2.

13. Sutton K, Clark S E, Thompson J, Craypo L, Schwarte L, Kuo T (2019): Contextual assessment of the breadth and level of investments made by prevention initiatives to improve nutrition and prevent obesity in Los Angeles Country, 2010-2015. Preventive Medicine Reports.15:1-7.

14. Molnár J, Ásványi B (2019): Studying growth characteristics of yeast strains on vegetal fermentation media and with vitamin supplementation. Acta Alimentaria.48:143-149.

15. Ayseli Y I, Aytekin N, Buyukkayhan D, Aslan I, Ayseli M T (2020). Food policy nutrition and nutraceuticals in the prevention and management of COVID-19: Advence for health care professionals. Trends in Food Science and Technology.105:186199.

16. Sun Y, Liguori K, Moussavi P, Mehta K (2015): Piloting a healthy street food venture in Kenya: Lessons learned. Procedia Engineering.107:417-426.

17. Privitera D, Nesci F S (2015): Globalization vs. local. The role of street food in the urban food system. Procedia Economics and Finance.22:716-722.

18. Alimi B A (2016). Risk factors in street food practices in developing countries: A review. Food Science and Human Wellness. 5:141-148.

19. Cortese R D M, Veiros M B, Felman C, Cavalli S B (2016): Food safety and hygiene practices of vendors during the chain of street food production in Florianopolis, Brazil: A cross-sectional study. Food Control.62:178-186.

20. Gupta V, Downs S M, Ghosh-Jerath S, Lock K, Singh A (2016): Unhealthy fat in street and snack foods in low socioeconomic settings in India: A case study of the food environments of rural villages and an urban slum. Journal of Nutrition Education and Behavior.48:269-279.e1.

21. Kharel N, Palni U, Tamang J P (2016): Microbiological assessment of ethnic street foods of the Himalayas. Journal of Ethnic Foods.3:235-241.

Online references:

22. Szántai Z $\mathrm{Z}$. https://www.youtube.com/watch?v=Tpuwm7cmp1M. (Awakening meditation introduction):2021.03.21. 